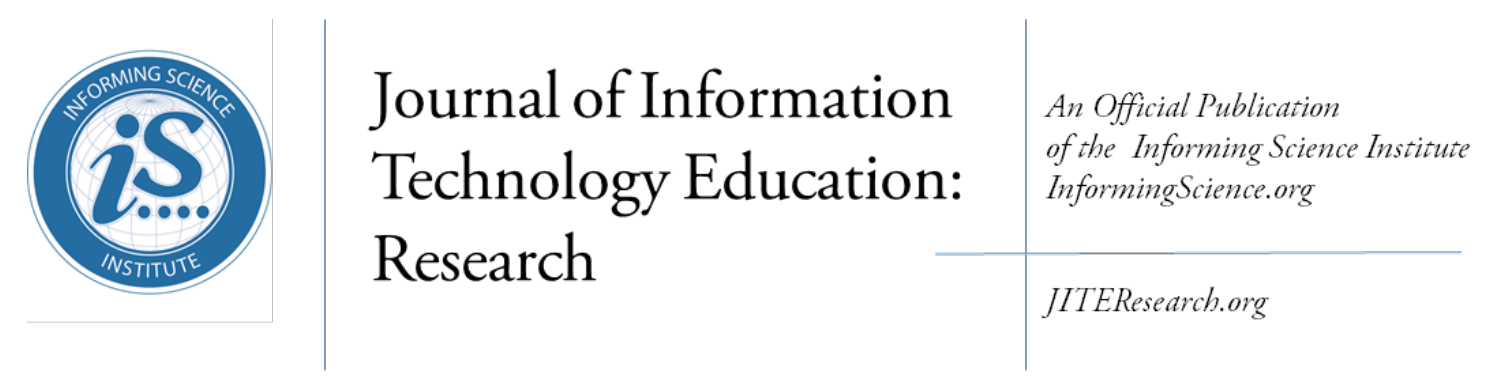

Volume 16, 2017

\title{
EXPLORING THE ROLE OF M-LEARNING IN ELEMENTARY EDUCATION
}

Hsiu-Ju Chen $\quad \begin{aligned} & \text { Department of Information Management, } \\ & \text { I-Shou University, Kaohsiung City, Taiwan }\end{aligned}$

ABSTRACT

Aim/Purpose This study explores the associations between elementary school learners' m-learning and learner satisfactions based on the technology-mediated learning model.

Background M-learning (mobile learning) is emerging, but its role in elementary education still needs clarification.

Methodology Questionnaires were mailed to several different elementary schools, located in different areas that adopted m-learning. Due to the possible limited cognitive ability because of age, short measures were adopted in the study. Finally, data from eighty-six elementary school learners who had experience in mobile learning were gathered and analyzed with Partial Least Square (PLS) for the limited sample size.

Contribution The results implied the vital role of $\mathrm{m}$-learning in providing different form of interaction in class to activate elementary school learners' course participation. They also indicated that mobile learning not only activated learners' active course participation but linked students, teachers, courses, and schools.

Findings

The results showed that m-technology quality of mobile learning was significantly associated with learners' active course participation and satisfaction toward apps/tablets in m-learning that contributed to different learner satisfactions.

Recommendations The findings suggested that with good interaction quality facilitated by for Practitioners apps/tablets in m-learning, m-learning could be a suitable medium for teachers to have interaction with students and increased students' different satisfactions in schools at alternative collective learning environments in elementary education.

Future Research Future studies to measure and reflect different impact of student-teacher interaction in m-learning are suggested.

Keywords

active course participation, $\mathrm{m}$-technology quality, satisfaction toward course satisfaction toward peers, satisfaction toward school

Accepted by Editor Tian Luo | Received: July 17, 2017 | Revised: August 23, September 17, October 2, 2017 | Accepted: October 5, 2017.

Cite as: Chen, H-J. (2017). Exploring the role of m-learning in elementary education. Journal of Information Technology Education: Research, 16, 459-474. https://doi.org/10.28945/3873

(CC BY-NC 4.0) This article is licensed to you under a Creative Commons Attribution-NonCommercial 4.0 International License. When you copy and redistribute this paper in full or in part, you need to provide proper attribution to it to ensure that others can later locate this work (and to ensure that others do not accuse you of plagiarism). You may (and we encourage you to) adapt, remix, transform, and build upon the material for any non-commercial purposes. This license does not permit you to use this material for commercial purposes. 


\section{INTRODUCTION}

With the wide popularity of apps/tablets in life, mobile learning (i.e., m-learning) has become feasible in recent years. Learning through mobile devices can ubiquitously occur due to the improving capabilities of mobile technology and increasing number of emerging apps. The mobility in learning facilitates catalyzing learners' rich and diverse interactions in various learning situations that are different from traditional education environment. Consequently, m-learning is flexible, but learnercentered.

Recently, m-learning has been adopted in primary education. Some elementary schools have used mobile devices, such as iPads or other tablets, for student learning. In the courses, teachers can directly assign individual or group tasks to students through apps on tablets inside or outside the classroom and gain responses from students with the aid of the wireless function of tablets. When the tasks are finished, students can also see others' responses projected on the whiteboards or shared through apps on tablets by teachers and group discussions. The game-like question/answer process enhances students' interactions with the teachers while learning. Students also have more interaction with their peers because they want to get tasks done in the process. As a result, with the design of different functions, m-learning increases not only the teacher-student interaction but also the student-student interaction in the learning process.

M-learning is a new paradigm of education, and it is different from the traditional e-learning. For learners and organizations, mobile technology is much less expensive than personal computers. However, mobile devices not only allow learners' access to existing resources of e-learning, but they enable learners to learn at different places (Valk, Rashid, \& Elder, 2010). M-learning facilitates the design of situated learning during course activities, such as botany outside the classroom or a general question-answer process inside the classroom (Valk et al., 2010), which empowers students to actively participate in their learning (Brown, 2003; dela Pena-Bandalaria, 2007; Valk et al., 2010). This raises the important issue of learner participation in a course with m-learning. In addition, m-learning facilitates and arouses learners' interest about the course and helps them see the relevance of what they are learning (Kukulska-Hulme \& Traxler, 2007; Traxler, 2007; Valk et al., 2010). It acts as a catalyst, which increases their interaction with others in elementary education. Learner satisfaction is of concern in education. This raises the other important issue, namely, exploring the association between learners' participation in the course of m-learning and different learning satisfactions that include satisfaction with their peers, with the teacher's teaching, with the course, and with the school.

The technology-mediated learning model has gained great attention in technology-related learning domains (e.g., Alavi \& Leidner, 2001; Arbaugh \& Duray, 2002). It provides a foundation for exploring the role of mobile technology in elementary school students' learning. This study, therefore, explores elementary school learners' new paradigm of m-learning in an empirical study based on the model. Following the literature, an exploratory study was made. The results of the study facilitate the understanding of the impact of $\mathrm{m}$-learning on learners in an elementary educational environment. The results also facilitate the administration of elementary schools in the adoption of mobile technology to activate learners in elementary education.

\section{THE TECHNOLOgY-MEDiATED LEARNING MODEL}

To indicate the role of technology in learning, Alavi and Leidner (2001) propose the technologymediated learning model. It involves technology capabilities, instructional strategy, psychological processes, and contextual factors about learning.

According to the model, participants, technology, and teaching strategies are interrelated. They further lead to participants' learning processes, including psychological processes and learning activities, and the learning processes contribute to the participants' learning outcomes (Alavi \& Leidner, 2001). The conceptual model of technology-mediated learning is shown in Figure 1. 


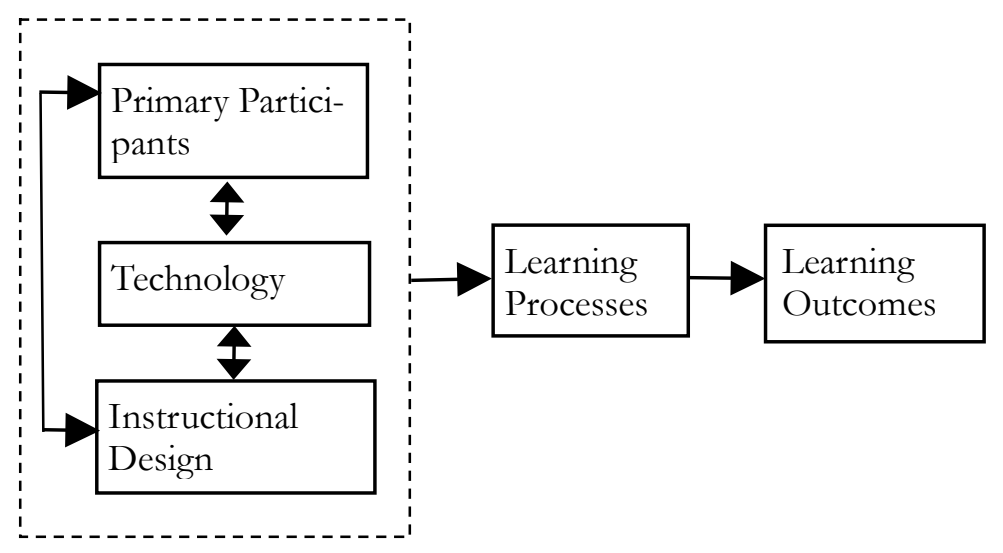

Figure 1. The conceptual model of technology-mediated learning adapted from Alavi \& Leidner (2001)

\section{M-LEARNING FOR INTERACTION}

In m-learning, mobile technology enables the learning to be a process of construction, such as finding, identifying, manipulating, and evaluating content for learning, rather than a mere instructional process (Brown, 2003; dela Pena-Bandalaria, 2007; Rikala, 2013; Valk et al., 2010). Learners do not passively receive information from the instructor (Valk et al., 2010). They gain greater control in the learning process of $\mathrm{m}$-learning. This provides an important motivator to learners, which is lacking in traditional modes of education but appeals to learners (Geddes, 2004; Valk et al., 2010).

M-technology quality of apps/tablets enables different forms of interaction between teachers and learners and also among learners. It allows learners to actively participate in the learning and to meaningfully construct their learning (Brown, 2003; dela Pena-Bandalaria, 2007; Valk et al., 2010). It also provides learners feedback in their learning process. According to the technology-mediated learning model, technology increases participants' learning activities in the learning processes (Alavi \& Leidner, 2001). This study is therefore motivated to validate the association of $\mathrm{m}$-technology quality of m-learning with learners' active course participation.

In addition, interpersonal interaction is believed to be associated with learning outcomes of course achievements and satisfaction (Baker, 1999; Buriel, 1983; Hughes, Carvell, \& Willson, 2001). Mlearning enables learners to interact with lecturers and peers in different forms (Goundar, 2011). It allows reaching underserved children in schools and supports alternative learning environments (McQuiggan, Kosturko, McQuiggan, \& Sabourin, 2015). Based on the technology-mediated model, participants' learning processes are associated with their learning outcome (Alavi \& Leidner, 2001). Learner satisfaction is of concern and reflects one of the learning outcomes of underserved children. A purpose of the study, therefore, is to validate the association of learners' participation with their learner satisfaction.

M-learning is emerging, and many elementary schools have adopted m-learning in the courses of different subjects with different teaching methods; however, its role in elementary education still needs clarification. Mobile technology provides interaction between participants and the learning context and facilitates participants' learning. It also acts as a wireless medium that activates interaction between teachers and students, as well as among the students. This study, therefore, intends to empirically explore the relationships among technology, learning processes, and learning outcomes in elementary school m-learning based on the technology-mediated learning model. The results help to depict the role of $\mathrm{m}$-learning in elementary education and provide references in adopting $\mathrm{m}$-learning to activate participants' learning. 


\section{RESEARCH HYPOTHESES}

M-learning is learner-centered (Cobcroft, Towers, Smith, \& Bruns, 2006; Diaz, 2010; Sharples, Taylor, \& Vavoula, 2005). This study, therefore, explores the relationships among technology, learning processes, and learning outcome based on learners' perceptions.

\section{THE IMPACT OF TECHNOLOGY ON LEARNING PROCESSES}

Alavi and Leidner (2001) indicate the importance of quality in the technology dimension. System quality is referred to as users' perception of the quality of their interaction with information systems (DeLone \& McLean, 1992). It guides users' operation and enables their good interaction with the systems as well as the interaction between the user and the situation.

Sun Tsai, Finger, Chen, and Yeh (2008) clarifiy the importance of technology quality in technologymediated learning. Tablets allow learners to use apps/functions of tablets for m-learning with larger touch screens in visual and operation, and also wireless function. These advantages enable flexible and different forms of interaction from those in traditional oral instruction course learning (Mueller, Wood, De Pasquale, \& Archer, 2011). This study, therefore, measures m-technology quality of apps/tablets of m-learning in the technology dimension.

M-technology quality reflects participants' interaction with mobile technology under teachers' different teaching methods. It can be achieved through the design of different system functions. Good mtechnology quality allows learners' sequence of responses with the technology in m-learning. It provides interaction between participants and the learning context and attracts participants' learning in fitting with the circumstances of teachers' different teaching methods in m-learning. Learners may thus be motivated to be more actively involved and spontaneously participate in the course because of the good interaction facilitated by the design of different forms of interaction provided through m-learning in the course (Fassinger, 1995; Holley \& Steiner, 2005; Martin, 1988; Rocca, 2010; Ryan \& Pintrich, 1997; Ryan, Pintrich, \& Midgley, 2001). In addition, when learners perceive good mtechnology quality, they may feel satisfaction toward the apps/tablets in m-learning. This study, therefore, measures learners' active course participation and satisfaction toward apps/tablets in the learning processes and clarifies the impact of m-technology quality on them. Finally, learners' active course participation can also possibly enhance their satisfaction toward apps/tablets in m-learning for learners are attracted in the course of learning. Based on Alavi and Leidner (2001), the following hypotheses are, therefore, proposed.

H1: M-technology quality as perceived by elementary school learners is significantly associated with their active course participation in m-learning.

H2: M-technology quality as perceived by elementary school learners is significantly associated with their satisfaction toward apps/tablets in m-learning.

H3: Elementary school learners' active course participation in m-learning is significantly associated with their satisfaction toward apps/tablets in m-learning.

\section{THE IMPACT OF LEARNING PROCESSES ON LEARNING OUTCOME}

The importance of teacher-student interaction has been shown in the learning outcomes of course achievement and satisfaction (Baker, 1999; Buriel, 1983; Hughes et al., 2001). The interaction is dynamic and continuous and can be activated or aided by effective media, such as text, words, behavior, or body language (Dunkin \& Biddle, 1974). M-learning provides a different form of interaction between teachers and students, and also among students from those in traditional oral instruction courses. With adequate spontaneous talking or question-asking in class, facilitated by functions of $\mathrm{m}$ learning, but not necessarily face-to-face, learners' active course participation can increase their satisfaction toward teacher's teaching because of the good interaction with teachers (Cazden, 1986; 
Mehan, 1980). They may also feel satisfaction toward their peers when the different forms of interaction enabled by m-learning in class satisfies their expectations among peers (Cazden, 1986; Mehan, 1980; Starmer, Duquette, \& Howard, 2015).

In addition, satisfaction toward apps/tablets of m-learning can possibly increase learners' satisfaction toward the peers because the media of $\mathrm{m}$-learning provides a different form for them to have interaction with peers in the course compared to the traditional oral instruction paradigm (Cazden, 1986; Mehan, 1980). They can have group discussions cooperatively, quickly get their answers submitted through apps on tablets in time, and wait for a teachers' explanation of correct solutions. This increases smooth peer interaction. Furthermore, satisfaction toward apps/tablets of m-learning can possibly increase learners' satisfaction with school because schools decide the classes and the courses that adopt the innovation of m-learning. School satisfaction refers to the students' subjective perception of the quality of his/her school life and it affects the youth's global life satisfaction (Suldo, Bateman, \& McMahan, 2014). M-learning allows a different form of learning at schools. This study therefore also measures the learners' satisfaction with the school in the learning outcome dimension, and it clarifies the impact of the learner's satisfaction with the apps/tablets of $\mathrm{m}$-learning in elementary school.

Finally, as students grow older, they need to learn to talk or ask questions in such a way that it satisfies the expectations of both their peers and teachers in class, even if the two expectations may be in conflict (Cazden, 1986; Mehan, 1980). As a result, satisfaction with a peer can also affect one's satisfaction with the teaching of a teacher because these interactions are linked. Furthermore, learners may also be satisfied with a course because they are satisfied with the teacher's teaching. A learners' satisfaction with the school may also be enhanced by their satisfaction with the course because they have had a positive experience of learning at school (Suldo et al., 2014). This study therefore also clarifies the impact of this.

Satisfaction encourages learners to keep on learning (Eom \& Arbaugh, 2011; Johnson, Najmuddin, Shaik, \& Palma-Rivas, 2000; Sun et al., 2008). To reflect learners' satisfactions at schools, this study measures learner satisfactions, including satisfaction toward peers, satisfaction toward teacher's teaching, satisfaction toward course, and satisfaction toward school, in the learning outcome dimension in elementary school learners' m-learning. Based on Alavi and Leidner (2001), the hypotheses about the impact of the learning processes dimension on the learning outcome dimension are therefore proposed.

H4: Elementary school learners' active course participation of m-learning is significantly associated with their satisfaction toward peers.

H5: Elementary school learners' active course participation of m-learning is significantly associated with their satisfaction toward teacher's teaching.

H6: Elementary school learners' satisfaction toward apps/tablets of m-learning is significantly associated with their satisfaction toward peers.

H7: Elementary school learners' satisfaction toward apps/tablets of m-learning is significantly associated with their satisfaction toward school.

H8: Elementary school learners' satisfaction toward peers is significantly associated with their satisfaction toward teacher's teaching.

H9: Elementary school learners' satisfaction toward teacher's teaching is significantly associated with their satisfaction toward course.

H10: Elementary school learners' satisfaction toward course is significantly associated with their satisfaction toward school. 
The conceptual model of the study is shown in Figure 2.

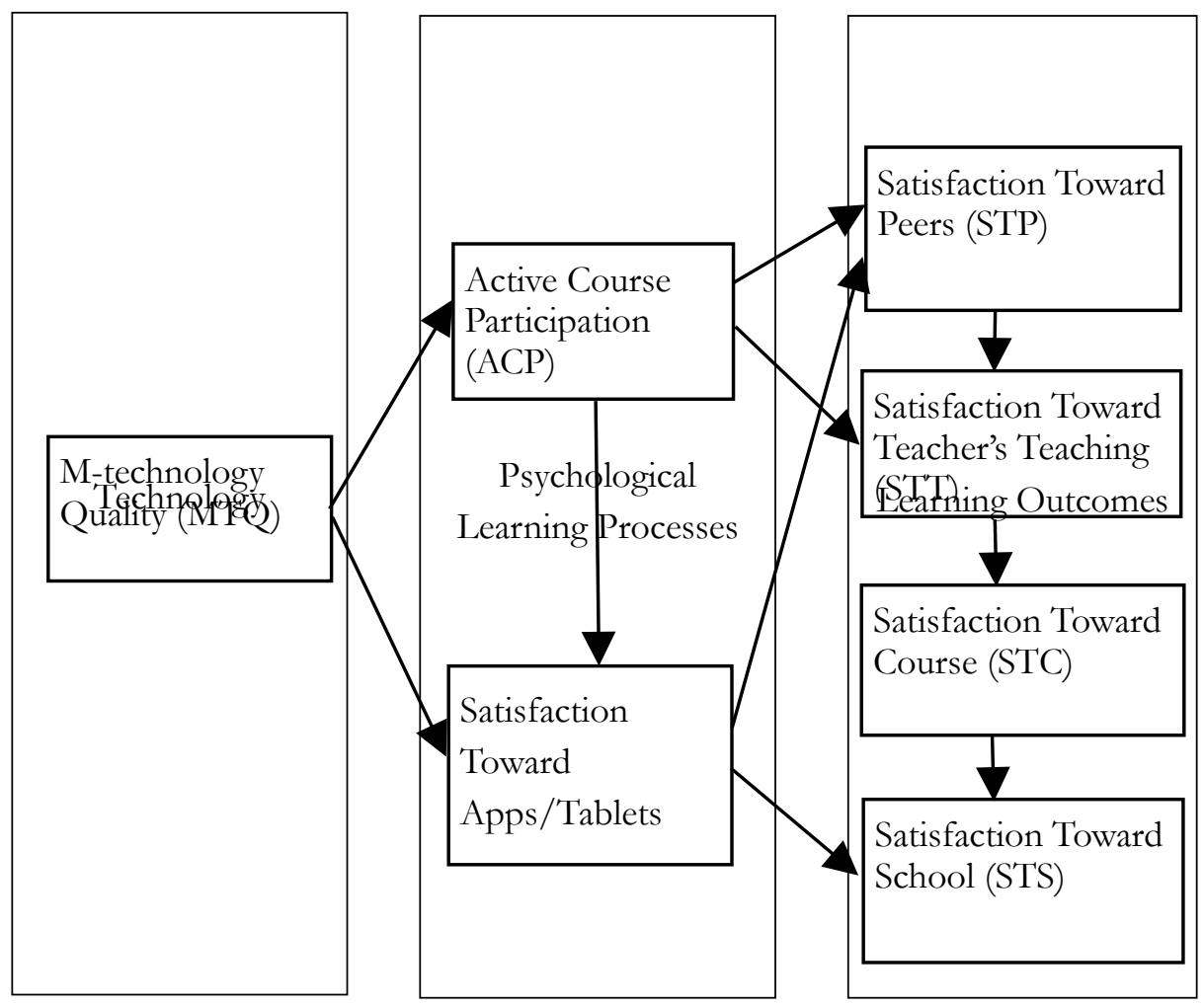

Figure 2. The conceptual model of the study.

\section{RESEARCH METHOD}

To empirically explore elementary school learners' m-learning, the survey method was adopted. Compared to other methods, the survey method commonly reflected the outcome of learner satisfaction in different courses with m-learning and was therefore used in the study. The study is empirically based on learners who had experience with m-learning in elementary education.

\section{MEASUREMENTS}

The constructs in this study include $\mathrm{m}$-technology quality, satisfaction toward apps/tablets of mlearning, active course participation, satisfaction toward peers, satisfaction toward teacher's teaching, satisfaction toward courses, and satisfaction toward school. A total of eleven question items describing the seven constructs were used. The measures and operational definitions adopted in this study were based on instruments and definitions in the extant literature. All the measurements were selfevaluated by elementary school learners on the Likert's five-point scale, ranging from (1)-strongly disagree to (5)-strongly agree. Their operational definitions are described below.

\section{M-technology quality}

Typical definitions and measures of system quality were adopted to reflect m-technology quality based on extant studies in this study (DeLone \& McLean, 1992; Seddon, 1997; Seddon \& Kiew, 1996; Sun et al., 2008). M-technology quality refers to an individual's perceived quality concerning the interaction of learning apps/tablets with m-learning, such as system responsiveness and a good interface for operation (Seddon, 1997). The measurements adopted were based on the study of Seddon and Kiew (1996). 


\section{Active course participation and satisfaction toward apps/tablets of m-learning}

Active course participation was defined as the learners' being spontaneous in their participation in the course of $\mathrm{m}$-learning in this study, such as spontaneously asking questions, spontaneously discussing the course with peers, etc. (Fassinger, 1995; Holley \& Steiner, 2005; Martin, 1988; Rocca, 2010; Ryan \& Pintrich, 1997; Ryan et al., 2001). The measure adopted was based on the studies of Fassinger (1995) and Martin (1988). Regarding satisfaction toward apps/tablets for m-learning, the traditional definition of satisfaction toward information systems based on DeLone and McLean (1992) and Seddon (1997) was adopted in this study. Satisfaction toward apps/tablets for m-learning refers to an individual's satisfying feelings about apps/tablets used in m-learning in this study (DeLone \& McLean, 1992; Seddon, 1997; Seddon \& Kiew, 1996). A global question was adopted.

\section{Satisfaction toward peers, satisfaction toward teacher's teaching, satisfaction toward course, and satisfaction toward school}

Finally, learner satisfaction refers to learners' diverse feelings of satisfaction, including satisfaction toward peers, satisfaction toward the teacher's teaching with mobile learning, satisfaction toward the course, and satisfaction toward the school in this study (Eom \& Arbaugh, 2011; Johnson, 2000; Sun et al., 2008). These measurements all adopted a single question.

Due to the possible limited cognitive ability because of age, short measures were adopted in the study. Before the formal survey, the questionnaire was pre-read by some students in the third year of elementary schools. The students indicated that they could easily understand the questionnaire. The questionnaire was then used in the formal survey.

\section{DATA COLLECTION}

To gather data, questionnaires were mailed to several different elementary schools that adopt $\mathrm{m}$ learning. These elementary schools are located in different areas and use m-learning in some of their courses. All these schools had applied projects and gained financial support for m-learning implementation from the Ministry of Education. However, not all students had computers or tablets connecting to the Internet. The paper questionnaires were then passed to students by schools. In about two months, only eighty-six valid questionnaires were gathered.

Table 1. The descriptive of the respondents

\begin{tabular}{ccc}
\hline \multicolumn{1}{c}{ Items } & Frequency & Percentage \\
\hline Gender & 44 & $51.2 \%$ \\
Male & 42 & $48.8 \%$ \\
\hline $\begin{array}{c}\text { Degree in Elementary Education } \\
\text { Sixth degree }\end{array}$ & 86 & $100 \%$ \\
\hline Weekly Internet Use Time & \\
Below 1 hour & 23 & $26.7 \%$ \\
1-3 hours & 40 & $46.5 \%$ \\
3-5 hours & 5 & $5.8 \%$ \\
5-7 hours & 6 & $7.0 \%$ \\
Above 7 hours & 12 & $14.0 \%$ \\
\hline
\end{tabular}


Exploring the Role of M-learning in Elementary Education

In filling the questionnaire, respondents were first asked if they were willing and agreed to answer the questionnaire. They were then asked to base their answers on their most impressive and recent mlearning course. The results indicated that all the respondents had experience in m-learning and were thus valid for the study. Among the respondents, all the students were in the sixth year of elementary schools. About gender, forty-two (48.8\%) of the respondents were female, and the others were male. Furthermore, regarding weekly Internet access time, most respondents (46.5\%) used the Internet between one to three hours a week, some $(26.7 \%)$ used the Internet less than one hour a week, and some $(14.0 \%)$ used the Internet for more than seven hours a week. A descriptive is shown in Table 1.

\section{DATA ANALYSIS}

There were a total of eighty-six valid respondents. With the limitation of sample size, the method of PLS was adopted for data analysis in this study. In these years, PLS has become a more commonly used method of data analysis (Hair, Hult, Ringle, \& Sarstedt, 2017). It uses bootstrapping for resampling and the partial least square method for coefficient estimation (Chin, 1998; Henseler, Ringle, \& Sinkovics, 2009). Therefore, the method relies less on sample size, but provides a good estimation of coefficients for precise interpretation (Chin, 1998; Henseler et al., 2009).

In verifying the hypotheses, this study adopted SmartPLS 2.0 for data analysis (Ringle, Wende, \& Will, 2005). And, according to Majchrzak, Malhotra, and John (2005), when the sample size is compared to the largest path number of the model, the sample size should be at least five to ten times larger. The study still conformed to the rule, and, therefore, data analysis was done. All the constructs were modeled to be reflective in the data analysis.

\section{Measurement validity}

In order to understand construct measures, both construct convergent validity and discriminate validity were used in the study (Komiak \& Benbasat, 2006). The results of Cronbach's $\alpha$ and the underlying factor structure were also provided.

Convergent Validity. Convergent validity indicates the consistency that multiple items exhibit in measuring a single construct. Uni-dimensionality, average variance extracted (AVE), and composite reliability (CR) are adequate indicators used for reflecting convergent validity (Bagozzi \& Yi, 1988; Steenkamp \& Van Trijp, 1991). They were therefore adopted in this study. Regarding unidimensionality, factor loading $(>0.5)$ and the t-value $(>1.96)$ of each question item were required. The results of AVE, CR and factor loading are provided in Table 2.

The results showed that all constructs had AVE values higher than 0.5 , and CR values higher than 0.7 . Furthermore, all constructs had Cronbach's $\alpha$ values greater than 0.7 . The factor loading and t-value of each question item were also acceptable, compared to their criteria. Overall, the results showed the acceptable convergent validity of the measurements (Chin, 1998; Fornell \& Larcker, 1981; Hair, Babin, Money, \& Samouel, 2003). 
Table 2. Average variance extracted (AVE), composite reliability (CR), and factor loading of construct measurement

\begin{tabular}{|c|c|c|c|c|c|c|c|c|c|c|c|}
\hline Constructs & Items & AVE & CR & Cronbach's $\alpha$ & MTQ & $\mathrm{ACP}$ & STAT & STP STT & STC & STS & t-value \\
\hline \multirow{3}{*}{$\begin{array}{l}\text { M-technology } \\
\text { Quality (MTQ) }\end{array}$} & MTQ1 & & & & 0.89 & 0.63 & 0.64 & 0.590 .44 & 0.54 & 0.46 & 30.89 \\
\hline & MTQ2 & 0.83 & 0.94 & 0.90 & 0.92 & 0.59 & 0.81 & 0.520 .46 & 0.39 & 0.44 & 53.26 \\
\hline & MTQ3 & & & & 0.92 & 0.47 & 0.73 & 0.570 .41 & 0.50 & 0.35 & 40.93 \\
\hline \multirow{3}{*}{$\begin{array}{l}\text { Active Course } \\
\text { Participation } \\
\text { (ACP) }\end{array}$} & ACP1 & & & & 0.55 & 0.87 & 0.47 & 0.580 .54 & 0.40 & 0.33 & 27.84 \\
\hline & ACP2 & 0.70 & 0.87 & 0.78 & 0.49 & 0.83 & 0.42 & $0.53 \quad 0.72$ & 0.49 & 0.34 & 14.68 \\
\hline & ACP3 & & & & 0.51 & 0.80 & 0.33 & 0.410 .39 & 0.46 & 0.31 & 9.72 \\
\hline $\begin{array}{l}\text { Satisfaction } \\
\text { Toward } \\
\text { Apps/Tablets } \\
\text { (STAT) }\end{array}$ & STAT1 & 1.00 & 1.00 & 1.00 & 0.80 & 0.49 & 1.00 & 0.570 .45 & 0.41 & 0.56 & - \\
\hline $\begin{array}{l}\text { Satisfaction } \\
\text { Toward Peers } \\
\text { (STP) }\end{array}$ & STP1 & 1.00 & 1.00 & 1.00 & 0.61 & 0.62 & 0.57 & 1.000 .66 & 0.58 & 0.41 & - \\
\hline $\begin{array}{l}\text { Satisfaction } \\
\text { Toward Teach- } \\
\text { er's Teaching } \\
\text { (STT) }\end{array}$ & STT1 & 1.00 & 1.00 & 1.00 & 0.48 & 0.68 & 0.45 & 0.661 .00 & 0.66 & 0.46 & - \\
\hline $\begin{array}{l}\text { Satisfaction } \\
\text { Toward Course } \\
\text { (STC) }\end{array}$ & STC1 & 1.00 & 1.00 & 1.00 & 0.52 & 0.53 & 0.41 & 0.580 .66 & 1.00 & 0.44 & - \\
\hline $\begin{array}{l}\text { Satisfaction } \\
\text { Toward School } \\
\text { (STS) }\end{array}$ & STS1 & 1.00 & 1.00 & 1.00 & 0.46 & 0.39 & 0.56 & 0.410 .46 & 0.44 & 1.00 & - \\
\hline
\end{tabular}

Discriminant Validity. For this, correlations between different constructs need to be lower than their own extracted variance explanations. The average variance extracted (AVE) and the crossloadings were included, to assess the validity in the study (Kerlinger \& Lee, 2000). The root square of the AVE of a construct should be greater than its correlation coefficients with other constructs (Chin, 1998; Fornell \& Larcker, 1981). In addition, the loadings of the construct should also be greater than their loadings on other constructs.

The results of correlations are shown in Table 3 , and the cross-loadings are provided in Table 2. All constructs, along with the square roots of the AVE's were greater than their correlation coefficients with other constructs. The loadings of all items on its construct were also greater than its loadings on other constructs. Overall, the results demonstrated acceptable measurement properties for all constructs. 
Table 3. Square Roots of Average Variance Extracted (AVE) and Pair-wise Correlations of the Constructs

\begin{tabular}{llllllll}
\hline Constructs & MTQ ACP & STAT & STP & STT & STC & STS \\
\hline M-technology Quality (MTQ) & $0.83^{\mathrm{a}}$ & & & & & & \\
Active Course Participation (ACP) & 0.62 & $0.91^{\mathrm{a}}$ & & & & & \\
Satisfaction Toward Apps/Tablets (STAT) & 0.80 & 0.49 & $1.00^{\mathrm{a}}$ & & & & \\
Satisfaction Toward Peers (STP) & 0.61 & 0.62 & 0.57 & $1.00^{\mathrm{a}}$ & & & \\
Satisfaction Toward Teacher's Teaching (STT) & 0.48 & 0.68 & 0.45 & 0.66 & $1.00^{\mathrm{a}}$ & & \\
Satisfaction Toward Course (STC) & 0.52 & 0.53 & 0.41 & 0.58 & 0.66 & $1.00^{\mathrm{a}}$ & \\
Satisfaction Toward School (STS) & 0.46 & 0.39 & 0.56 & 0.41 & 0.46 & 0.44 & $1.00^{\mathrm{a}}$ \\
\hline \multicolumn{2}{c}{ a: The square roots of AVEs are shown on the main diagonal. } & & & & & &
\end{tabular}

\section{Path Analysis Results}

With the adequacy in both convergent validity and discriminant validity of the measures, the results of empirical hypotheses testing were then provided. The SmartPLS analysis results are shown in Figure 3.

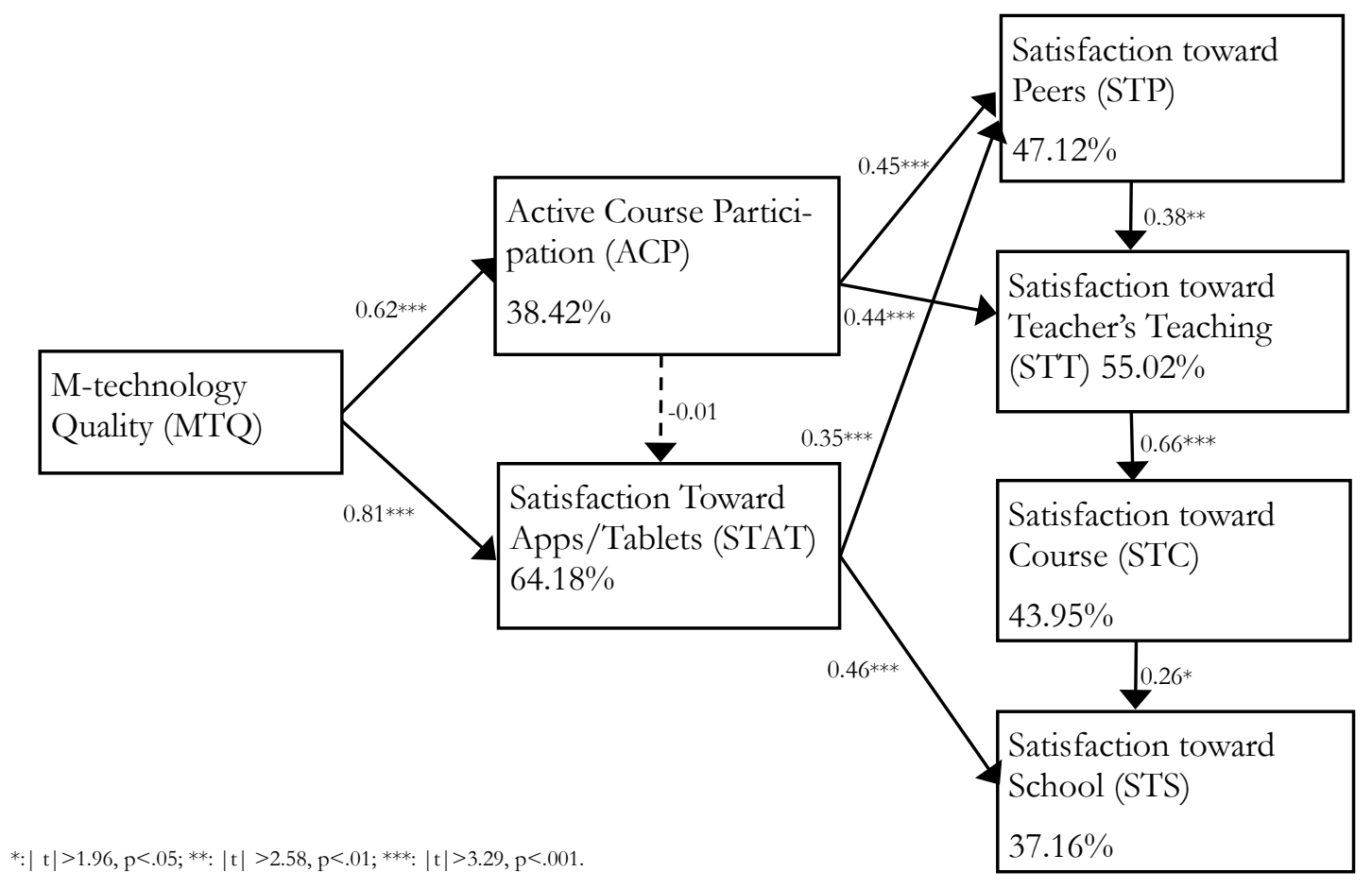

Figure 3. The results of the study.

\section{THE RESULTS OF THE IMPACT OF M-TECHNOLOGY QUALITY}

The results of this study showed that m-technology quality was significantly positively associated with elementary school learners' active course participation and satisfaction toward apps/tablets of m-learning. However, the impact of active course participation on satisfaction toward apps/tablets 
of m-learning was not shown to be significant. Therefore, the hypotheses of H1 and H2 were supported, but the hypothesis of $\mathrm{H} 3$ was rejected.

The results indicated the importance of m-technology quality in mobile learning to elementary school learners in their educational environment. It not only activated learners' active course participation, such spontaneous question asking and spontaneous discussion with peers, but also enhanced their satisfaction toward apps/tablets of m-learning.

\section{THE RESULTS OF THE IMPACT OF ACTIVE COURSE PARTICIPATION AND SATISFACTION TOWARD APPS/TABLETS OF M-LEARNING}

In addition, active course participation was shown to have a significantly positive association with satisfaction toward peers and satisfaction toward teacher's teaching. Satisfaction toward apps/tablets of m-learning was also shown to have a significantly positive association with satisfaction toward peers and satisfaction toward school. Therefore, the hypotheses H4, H5, H6, and $\mathrm{H} 7$ were not rejected but supported.

Furthermore, satisfaction toward peers was shown to have a significant impact on satisfaction toward teacher's teaching, and satisfaction toward teacher's teaching was shown to have a significant impact on satisfaction toward the course. Satisfaction toward course was also shown to significantly increase satisfaction toward school. Therefore, the hypotheses H8, H9, and $\mathrm{H} 10$ were not rejected but were supported.

The results showed the importance of active course participation in arousing satisfaction toward peers and satisfaction toward teacher's teaching. They also indicated the importance of satisfaction toward apps/tablets of m-learning in enhancing satisfaction toward peers and satisfaction toward school. Finally, learners' satisfaction toward peers also increased their satisfaction toward teacher's teaching. Their satisfaction with the teacher's teaching also enhanced their satisfaction with the course, which further increased satisfaction with school.

\section{DISCUSSION}

Most studies about m-learning focus on independent learning. Nonetheless, the role of $\mathrm{m}$-learning in elementary education needs clarification. The association of learners' m-learning with their learning outcomes of different levels of learning satisfaction was not clear either. Based on the technologymediated learning model, an exploratory study about elementary school learners' m-learning was made. The results provided considerable support for the model.

\section{THE IMPACT OF M-TECHNOLOGY QUALITY ON LEARNING PROCESSES}

The results of the study showed that in primary education, elementary school learners' perception of $\mathrm{m}$-technology quality of $\mathrm{m}$-learning enhanced their active course participation in the learning processes dimension. M-learning was provided as a different medium for teachers to teach and interact with learners; it also provided a medium for interaction among learners in collective learning environments. Learners' interaction with others was thus mediated by the apps and tablets of m-learning in the course. The interaction with others then becomes easier and, therefore, activates their active forms of course participation such as spontaneous question-asking.

Spontaneous question-asking needs not only learners' self-efficacy of the course and achievement motivation, but also their self-efficacy of social interaction (Fassinger, 1995; Holley \& Steiner, 2005; Jones \& Gerig, 1994; Rocca, 2010; Ryan \& Pintrich, 1997; Ryan et al., 2001). In m-learning, the results indicated that the m-technology quality of m-learning helped to activate learners' questionasking in elementary education environments, which was different from the interaction in traditional oral instruction class paradigms. The results provided references to teachers about the adoption of m-learning to activate students' course participation when students were not active in the course. 
The results also showed that learners' perception of m-technology quality increased their satisfaction with apps and tablets of $\mathrm{m}$-learning. The results indicated that $\mathrm{m}$-technology quality provided good interaction for learners and therefore enhanced their satisfaction with the apps and tablets of $\mathrm{m}$ learning.

M-learning facilitates the learning process of instructional methods for learning (Valk et al., 2010). The results reflected that $\mathrm{m}$-learning provided a good medium for different forms of interaction from those in traditional oral instruction paradigms and corresponded to Cazden's (1986) and Mehan's opinions (1980) about the importance of interaction in participants' learning. The results also corresponded to Alavi and Leidner (2001) about the importance of technology quality in learners' perception of their learning processes in technology-mediated learning.

\section{THE IMPACT OF LEARNING PROCESSES ON LEARNING OUTCOME OF DIFFERENT LEARNER SATISFACTIONS}

The results of the study also validated that active course participation and satisfaction with apps tablets of m-learning significantly increase learners' satisfaction with their peers. The results also showed that active course participation, as well as satisfaction toward peers, significantly increased learners' satisfaction toward teachers' teaching, which significantly enhanced learners' satisfaction toward the course. The results indicated the importance of both active course participation and satisfaction toward apps/tablets of m-learning in contributing to participants' learning satisfaction.

The results reflected that active course participation, facilitated by $\mathrm{m}$-learning to increase interaction with others and the learning situations, enhanced learning satisfaction toward peers and toward the teachers' teaching. The results reflected the importance of active course participation on the dimension of learning outcomes of different learner satisfaction in m-learning. Students' spontaneous question-asking deepens their understanding of learning content and facilitates their learning, whereas limited talking or question-asking does not facilitate learning (Good, Slaying, Harel, \& Emerson, 1987; Jones, 1990; Jones \& Gerig, 1994; King, 1992). The results corresponded to the former studies.

The results also indicated that satisfaction toward apps/tablets of m-learning increase satisfaction toward peers, reflecting that satisfaction toward apps/tablets of m-learning facilitated to fulfill learners' peer expectations. User satisfaction has been found to be important in facilitating the information systems success (DeLone \& McLean, 1992). The results revalidated its importance.

Furthermore, the results also indicated that learners' satisfaction toward teachers' teaching is further linked to their satisfaction of the course. The phenomenon demonstrated that learners' satisfaction toward the teacher's teaching guided their satisfaction toward the subject they were learning. Satisfaction toward the teacher's teaching aroused learners' sense of relevance and interest in the course. This reflected the importance of teachers in students' subject learning in elementary education.

The results also showed the importance of the roles of both teacher and peers in the learning situation (Cazden, 1986; Mehan, 1980). They corresponded to Starmer et al. (2015) regarding the importance of active course participation and teacher-student interaction satisfaction in the learning outcome of course satisfaction in m-learning (Baker, 1999; Buriel, 1983; Hughes et al., 2001).

Finally, the results validated that the impact of satisfaction toward apps/tablets and satisfaction toward the course enhanced learners' satisfaction toward school. In youth, global life satisfaction is thought to be primarily affected by their satisfaction with family, friendships, living environment, self, and school (Suldo et al., 2014). The results corresponded to Suldo et al. (2014) and indicated that mlearning, providing a different form of learning at schools, facilitated students' subjective perception of the quality of their school life. The results also corresponded to Alavi and Leidner (2001) regarding the impact ofparticipants' learning processes on their learning outcomes. 


\section{CONCLUSION}

Learners have different forms of satisfaction at schools. M-learning provides a different form of interaction in learning. Nonetheless, the empirical association of learners' $m$-learning with their different learning satisfactions is lacking. This study empirically validates elementary school learners' $\mathrm{m}$ learning based on the technology-mediated learning model in the elementary education environment. The results showed that m-technology quality facilitated learners' satisfaction toward apps/tablets and active course participation that led to their different learning satisfactions. The results implied the vital role of $\mathrm{m}$-learning in providing different forms of interaction in class to activate elementary school learners' course participation. They suggested that with good interaction quality facilitated by apps/tablets of m-learning, m-learning could be a suitable medium for teachers to have interaction with students and activate their learning in the collective elementary education environment.

The results also implied the crucial impact of learners' satisfaction toward apps/tablets and active course participation in the mediation between $\mathrm{m}$-technology quality and learner satisfactions. They suggested that the design of apps/tablets for m-learning has to first achieve learners' satisfaction toward apps/tablets and active course participation in arousing learners' different satisfactions in the elementary education environment. The results also indicated the important role of mobile learning in linking students, teachers, course, and school. The learning benefited underserved children in schools at alternative collective learning environments in elementary education.

The results provide references to school administrators who intend to lead teachers in the adoption of the new paradigm of $\mathrm{m}$-learning for future school development. The results also provide references to the designers of apps and tablets for m-learning in elementary education environments.

\section{LIMITATIONS AND SUGGESTIONS}

The technology-mediated learning model is a conceptual model. Its application to different learning technologies needs further clarification. Furthermore, student-teacher interaction is a process variable that reflects actual learning activities of learners. Future studies to measure and reflect different impacts of student-teacher interaction are also suggested.

\section{ACKNOWLEDGEMENTS}

The author would like to thank the editor and the anonymous reviewers for their help to the study.

\section{REFERENCES}

Alavi, M., \& Leidner, D. E. (2001). Research commentary: Technology-mediated learning - A call for greater depth and breadth of research. Information Systems Research, 12(1), 1-10. https://doi.org/10.1287/isre.12.1.1.9720

Arbaugh J. B., \& Duray, R. (2002). Technological and structural characteristics, student learning and satisfaction with web-based courses_-An exploratory study of two on-line MBA programs. Management Learning, 33(3), 331-347. https://doi.org/10.1177/1350507602333003

Bagozzi, R. P., \& Yi, Y. (1988). On the evaluation of structural equation models. Journal of the Academy of Marketing Science, 16(1), 74-94. https://doi.org/10.1007/BF02723327

Baker, J. A. (1999). The "teacher's pet" phenomenon, students' perceptions of teachers' differential behavior, and students' morale. Journal of Educational Psychology, 87, 361-374.

Brown, T. H. (2003). The role of m-learning in the future of e-learning in Africa? In Proceedings of 21st ICDE World Conference, June 2003.

Buriel, A. (1983). Teacher-student interactions and their relationship to student achievement: A comparison of Mexican-American and Anglo-American children. Journal of Educational Psychology, 75, 889-897. https://doi.org/10.1037/0022-0663.75.6.889 
Exploring the Role of M-learning in Elementary Education

Cazden, C. B. (1986). Classroom disclosure. In M. Wittrock (Eds.), Handbook of research on teaching (3rd ed.). New York: Plenum.

Chin, W. W. (1998). Issues and opinion on structural equation modeling. MIS Quarterly, 22(1), vii-xvi.

Cobcroft, R.S., Towers, S., Smith, J., \& Bruns, A. (2006). Mobile learning in review: Opportunities and challenges for learners, teachers, and institutions. In Proceedings of Online Learning and Teacbing (OLT) Conference 2006 (pp.21-30), Queensland University of Technology, Brisbane.

dela Pena-Bandalaria, M. (2007). Impact of ICTs on open and distance learning in a developing country setting: The Philippine experience. International Review of Research in Open and Distance Learning, 8(1), 1-15.

DeLone, W. H., \& McLean, E. R. (1992). Information systems success: The quest for the dependent variable. Information Systems Research, 3(1), 60-95. https://doi.org/10.1287/isre.3.1.60

Diaz, V. (2010). Mobile teaching and learning: Engaging students and measuring impact. Presentation at the 2010 EDUCAUSE Center for Applied Research Symposium, Carlsbad, CA, December 7, 2010, available from http://www.educause.edu/ecar

Dunkin, M. J., \& Biddle, B. (1974). The study of teaching. New York: Holt, Rinehart and Winston.

Eom, S. B., \& Arbaugh, J. B. (2011). Student satisfaction and learning outcomes in e-learning: An introduction to empirical research. IGI Global (e-book). https://doi.org/10.4018/978-1-60960-615-2

Fassinger, P. A. (1995). Professors' and students' perceptions of why students participate in class. Teaching Sociology, 24, 25-33. https://doi.org/10.2307/1318895

Fornell, C., \& Larcker, D. F. (1981). Structural equation models with unobservable variables and measurement errors. Journal of Marketing Research, 18(1), 39-50. https://doi.org/10.2307/3151312

Geddes, S. J. (2004). Mobile learning in the 21st century: Benefit for learners. Knowledge Tree e-journal: An Ejournal of Flexible Learning in VET, 30(3), 214-218.

Good, T. L., Slaying, R. L., Harel, K. H., \& Emerson, H. (1987). Student passivity: A study of question asking in K-12 classrooms. Sociology of Education, 60, 181-199. https://doi.org/10.2307/2112275

Goundar, S. (2011). What is the potential impact of using mobile devices in education? Proceedings of SIG GlobDev Fourth Annual Workshop, Shanghai, China - December 3, 2011.

Hair, J. F., Babin, B., Money, A. H., \& Samouel, P. (2003). Essentials of business research methods. USA: John Wiley $\&$ Sons.

Hair, J. F., Jr., Hult, G. T. M., Ringle, C., \& Sarstedt, M. (2017). A primer on partial least squares structural equation modeling (PLS-SEM). Thousand Oaks: Sage.

Henseler, J., Ringle, C.M., \& Sinkovics, R. R. (2009). The use of partial least squares path modeling in international marketing. Advances in International Marketing, 20, 277-319. https://doi.org/10.1108/S14747979(2009)0000020014

Holley, L. C., \& Steiner, S. (2005). Safe space: Student perspectives on classroom environment. Journal of Social Work Education, 41, 49-63. https://doi.org/10.5175/JSWE.2005.200300343

Hughes, J. N., Cavell, T. A., \& Willson, V. (2001). Further support for the developmental significance of the quality of the teacher-student relationship. Journal of School Psychology, 39, 289-301. https://doi.org/10.1016/S0022-4405(01)00074-7

Johnson, S. D., Najmuddin, S. R., Shaik, N., \& Palma-Rivas, N. (2000). Comparative analysis of learner satisfaction and learning outcomes in online and face-to-face learning environments. Journal of Interactive Learning Research, 11(1), 29-49.

Jones, M. G. (1990). Action zone theory, target students and science classroom interactions. Journal of Research in Science Teaching, 27, 651-660. https://doi.org/10.1002/tea.3660270705

Jones, M. G.., \& Gerig, T. M. (1994). Silent sixth-grade students: Characteristics, achievement, and teacher expectations. The Elementary School Journal, 95, 169-183. https://doi.org/10.1086/461797 
Kerlinger, F. N., \& Lee, H. B. (2000). Foundations of behavioral research (4th ed.). Australia: Wadsworth Thomson Learning.

King, A. (1992). Facilitating elaborative learning through guided student-generated questioning. Educational Psychologist, 27, 111-126. https://doi.org/10.1207/s15326985ep2701 8

Komiak, S. Y. X., \& Benbasat, I. (2006). The effects of personalization and familiarity on trust and adoption of recommendation agents. MIS Quarterly, 30(4), 941-960. https://doi.org/10.2307/25148760

Kukulska-Hulme, A., \& Traxler, J. (2007). Designing for mobile and wireless learning. In H. Beetham \& R. Sharpe (Eds.), Rethinking pedagogy for a digital age: Designing and delivering e-learning (pp. 180-192). London: Routledge.

Majchrzak, A., Malhotra, A., \& John, R. (2005). Individual know-how development in distributed groups: IT enabled contextualization. Information Systems Research, 16(1), 9-27. https://doi.org/10.1287/isre.1050.0044

Martin, C. L. (1988). Enhancing children's satisfaction and participation using a predictive regression model of bowling performance norms. The Physical Educator, 45(4), 196-209.

McQuiggan, S., Kosturko, L., McQuiggan, J., \& Sabourin, J. (2015). Mobile learning: A handbook for developers, educators, and learners. Hoboken, NJ: John Wiley \& Sons. https://doi.org/10.1002/9781118938942

Mehan, H. (1980). The complete student. Anthropology and Education, 11(3), 131-152. https://doi.org/10.1525/aeq.1980.11.3.05x1865s

Mueller, J., Wood, E., De Pasquale, D., \& Archer, K. (2011). Students learning with mobile technologies in and out of the classroom. In A. Mendez-Vilas (Ed), Education in a technological world: Communicating current and emerging research and technological efforts, pp. 414-420.

Rikala, J. (2013). Mobile learning - A review of current research. Reports of the Department of Mathematical Information Technology Series E. Educational Technology No.E 2/2013, University of Jyväskylä, Finland.

Ringle, C. M., Wende, S., \& Will, S. (2005). SmartPLS 2.0 (M3) Beta. Hamburg. Retrieved from http://www.smartpls.de

Rocca, K. A. (2010). Student participation in the college classroom: An extended multidisciplinary literature review. Communication Education, 59, 185-213. https://doi.org/10.1080/03634520903505936

Ryan, A. M., \& Pintrich, P. R. (1997). "Should I ask for help?” The role of motivation and attitudes in adolescents' help seeking in math class. Journal of Educational Psychology, 89, 329-341. https://doi.org/10.1037/0022-0663.89.2.329

Ryan, A. M., Pintrich, P. R., \& Midgley, C. (2001). Avoiding seeking help in the classroom: Who and Why? Educational Psychology Review, 13, 93-114. https://doi.org/10.1023/A:1009013420053

Seddon, P. B. (1997). A respecification and extension of the DeLone and McLean Model of IS success. Information Systems Research, 8(3), 240-253. https://doi.org/10.1287/isre.8.3.240

Seddon, P. B., \& Kiew, M. Y. (1996). A partial test and development of DeLone and Mclean's model of IS success. Australian Journal of Information Systems, 4(1), 90-109. https://doi.org/10.3127/ajis.v4i1.379

Sharples, M., Taylor, J., \& Vavoula, G. (2005). Towards a theory of mobile learning. Proceedings of mLearn 2005. Retrieved March 6 from http://mlearn.org.za/CD/papers/Sharples-\%20Theory\%20Mobile.pdf

Starmer, D. J., Duquette, S., \& Howard, L. (2015). Participation strategies and student performance: An undergraduate health science retrospective study. The Journal of Chiropractic Education, 29(2), 134-138. https://doi.org/10.7899/JCE-14-20

Steenkamp, J. E. M., \& Van Trijp, H. C. M. (1991). The use of LISREL in validating marketing constructs. International Journal of Research in Marketing, 8(4), 283-299. https://doi.org/10.1016/0167-8116(91)90027-5

Suldo, M. S., Bateman, L., \& McMahan, M. (2014). School satisfaction. Encyclopedia of Quality of Life and WellBeing Research, 5707-5712. https://doi.org/10.1007/978-94-007-0753-5_2601 
Exploring the Role of M-learning in Elementary Education

Sun, P.-C., Tsai, R. J., Finger, G., Chen, Y.-Y., \& Yeh, D. (2008). What drives a successful e-learning? An empirical investigation of the critical factors influencing learner satisfaction. Computers \& Education, 50(4), 11831202. https://doi.org/10.1016/i.compedu.2006.11.007

Traxler, J. (2007). Defining, discussing and evaluating mobile learning: The moving finger writes and having writ... The International Review of Research in Open and Distance Learning, 8(2). https://doi.org/10.19173/irrodl.v8i2.346

Valk, J. H., Rashid, A. T., \& Elder, L. (2010). Using mobile phones to improve educational outcomes: An analysis of evidence from Asia. International Review of Research in Open and Distance Learning, 11(1), 117-140. https://doi.org/10.19173/irrodl.v11i1.794

\section{BIOGRAPHY}

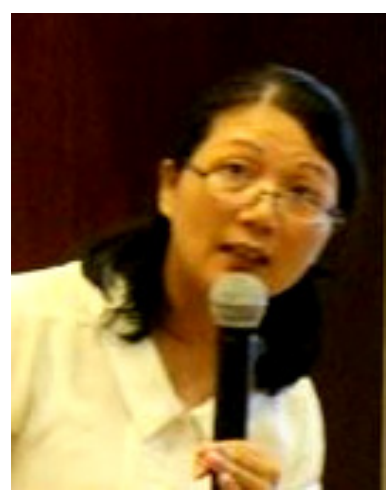

Hsiu-Ju Chen is an associate professor in Department of Information Management, I-Shou University. Her research interests mainly focus on m-learning, e-learning, information systems user behavior, etc. 